\title{
Renal Pelvis Squamous Cell Carcinoma and Renal Cell Carcinoma in a Tuberculous Kidney
}

\author{
M. Al-Assiri ${ }^{1}$, M.F. Al-Otaibi ${ }^{1}$, K. Sircar ${ }^{2}$, and M. Laplante ${ }^{1}$ \\ ${ }^{1}$ Department of Urology at Montreal General Hospital, McGill University, Montreal; \\ ${ }^{2}$ Department of Pathology at Montreal General Hospital, McGill University, Montreal \\ E-mail: manaalassiri@yahoo.com
}

Received September 5, 2004; Revised October 23, 2004; Accepted October 27, 2004; Published November 18, 2004

KEYWORDS: carcinoma, renal cell, squamous cell, tuberculosis, renal

DOMAIN: urology, pathology

\section{INTRODUCTION}

Squamous cell carcinoma (SCC) of the renal pelvis is a rare entity, usually associated with chronic inflammation and/or infection. There have been several reports of SCC in tuberculous kidneys, however, to the best of our knowledge, we report the first case of a tuberculous kidney with both squamous and renal cell carcinoma (RCC) combined in one kidney.

\section{CASE}

A 70-year-old male presented to the emergency room with left flank pain and fever. He was treated for renal tuberculosis 30 years prior to his presentation. Physical exam revealed left costoverteberal angle tenderness, while laboratory exam demonstrated leukocytosis and pyuria. Serum renal function tests were normal. He was initially treated as an acute pyelonephritis with intravenous antibiotics. A CT scan of the abdomen and pelvis showed an enhancing mass at the lower pole of the left kidney; further work-up shows no evidence of metastasis. He subsequently underwent a left radical nephrectomy with an uneventful postoperative course. Pathological findings were consistent with old renal tuberculosis (Fig. 1), SCC of renal pelvis (Fig. 2), and RCC (Fig. 3).

Patient has no evidence of metastasis after 3 years follow-up.

\section{DISCUSSION}

Genitourinary tuberculosis occurs in approximately $15 \%$ of patients with pulmonary tuberculosis in developing countries[1]. SCC of the renal pelvis is a rare entity and represents less than $0.7-7 \%$ of renal pelvic tumors[2]. As with other sites in the genitourinary tract, SCC are usually secondary to chronic inflammatory processes, which is not surprising in a tuberculous kidney. 


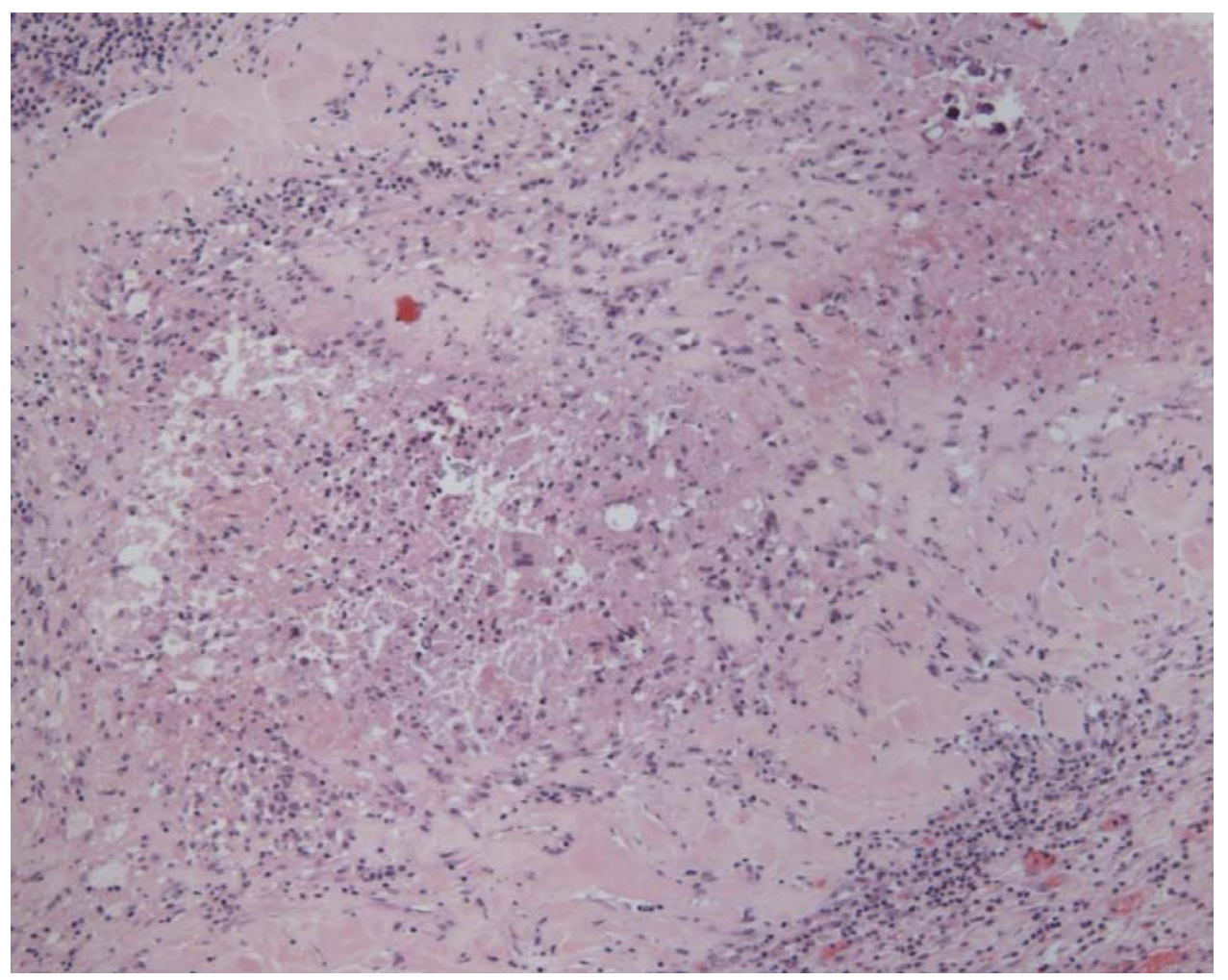

FIGURE 1

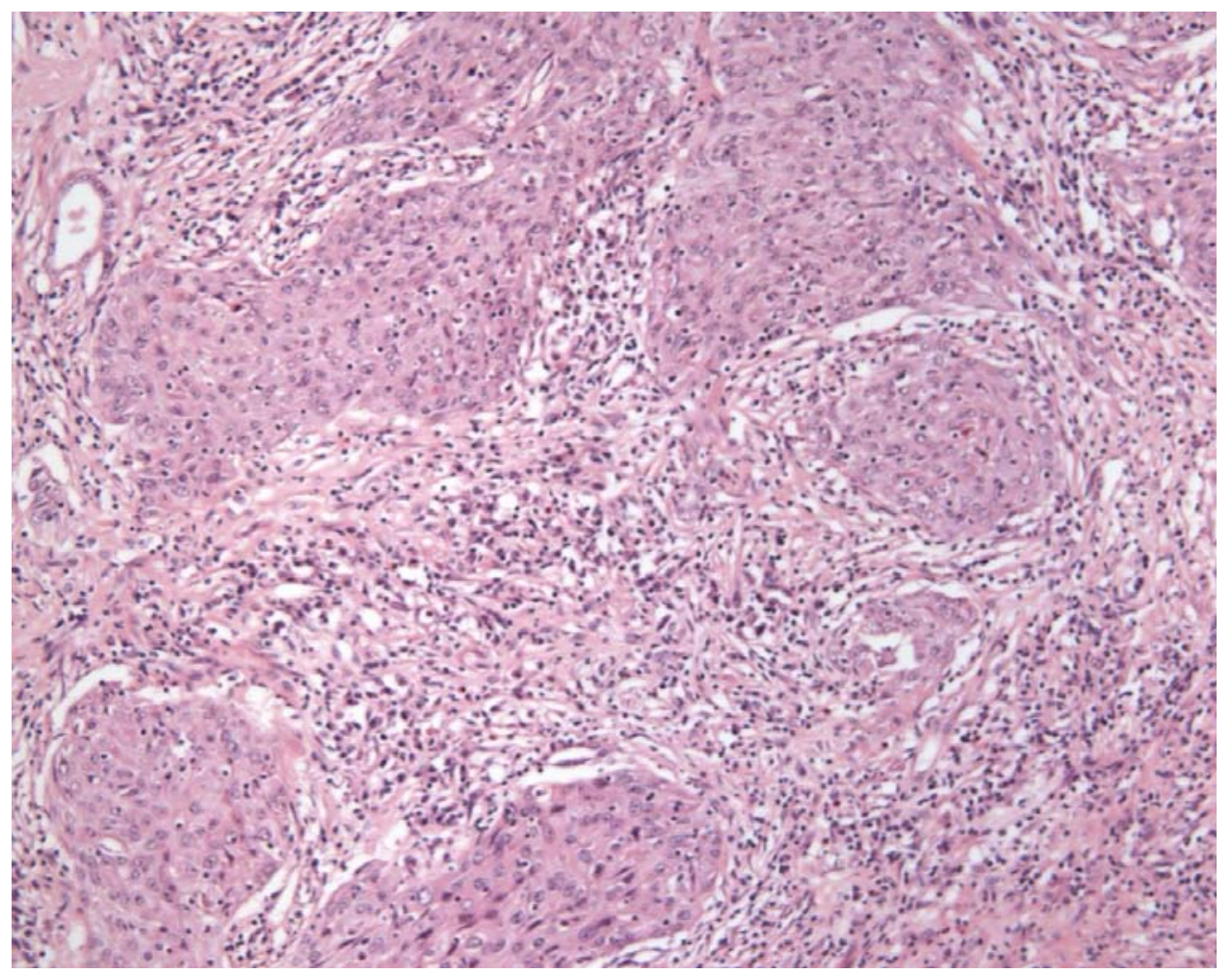

FIGURE 2 


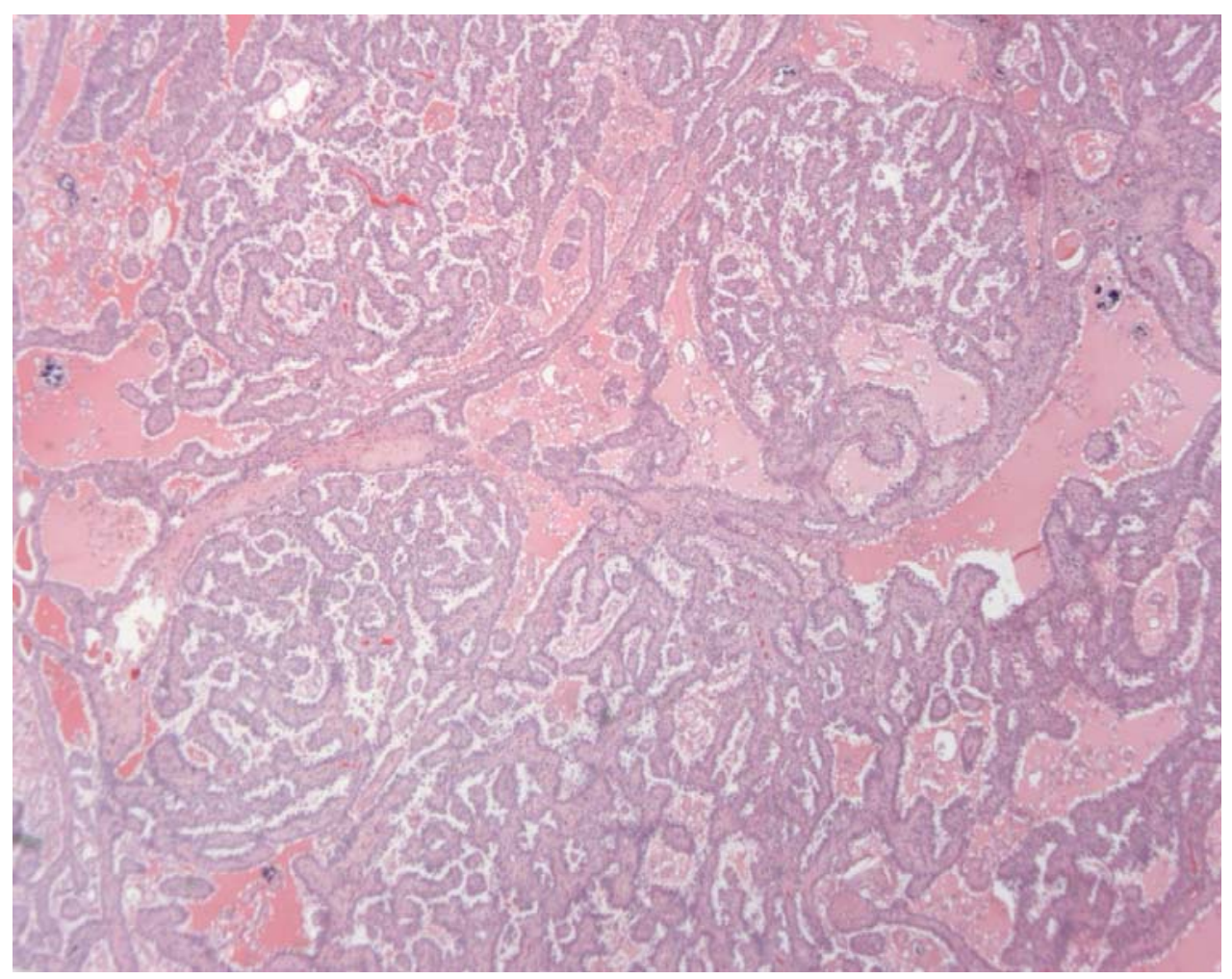

FIGURE 3

Preoperative recognition of SCC is very difficult since the symptoms will be obscured by stone presence. The presenting symptoms are abdominal pain, hematuria, constitutional symptoms, and palpable mass. Although SCC is not considered multifocal disease[3], a radical nephroureterctomy with bladder cuff excision is the preferred surgical intervention. Nephrectomy for renal tuberculosis is controversial, however, sepsis, pain, bleeding, hypertension, or suspected malignancies are considered indications for nephrectomy.

Approximately 45 cases of RCC in tuberculous kidneys have been reported in the literature. However, there have not been recommendations to follow these patients; this may be related to the rarity of tuberculosis in the west, which is not the case in other parts of the world like India and other developing countries in which tuberculosis is endemic.

Surveillance of GU tuberculosis with ultrasound of the kidney may be warranted to detect neoplastic pathology at early stages especially in those countries where tuberculosis is endemic. However, a pulmonary tuberculosis patient should not be screened routinely for GU tuberculosis unless the patient has clinical symptoms that are suggestive of GU tuberculosis.

The causative relationship of tuberculosis and RCC is rather complicated especially if we know from previous literature[4] that BCG interaction with uroepithelium upregulates interleukins and various interferons, which are the primary immunotherapy for RCC today.

\section{CONCLUSION}

We report the first case in the world where these three pathologies coexist in one kidney. 


\section{REFERENCES}

1. Freedman, L.R. (1979) In Strauss and Welt's Diseases of the Kidney. 3rd ed. Earley L.E. and Gottschalk, C.W., Eds. Little, Brown, Boston. p. 859.

2. $\quad$ Babaian, R.J. and Johnson, D.E. (1980) Primary carcinoma of the ureter. J. Urol. 123, 357.

3. Blacher, E.J., Johnson, D.E., Abdul-Karim, F.W., and Ayala, A.G. (1985) Squamous cell carcinoma of renal pelvis. Urology 25(2), 124-126.

4. Watanabe, E., Matsuyama, H., Matsuda, K., Ohmi, C., Tei, Y., Yoshihiro, S., and Ohmoto, Y. (2003) Urinary interleukin-2 may predict clinical outcome of intravesical bacillus Calmette-Guerin immunotherapy for carcinoma in situ of the bladder. Cancer Immunol. Immunother. 52(8), 481-486. Epub 2003 Apr 18.

This article should be referenced as follows:

Al-Assiri, M., Al-Otaibi, M.F., Sircar, K., and Laplante, M. (2004) Renal pelvis squamous cell carcinoma and renal cell carcinoma in a tuberculous kidney. TheScientificWorldJOURNAL 4, 965-968.

\section{Handling Editor:}

Anthony Atala, Principal Editor for Urology and Tissue Engineering — domains of TheScientificWorldJOURNAL. 


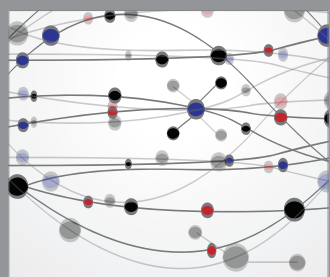

The Scientific World Journal
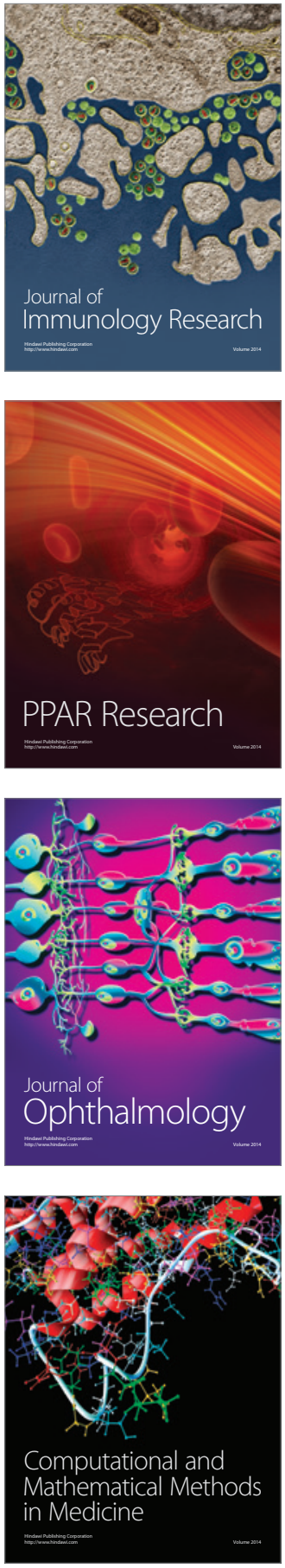

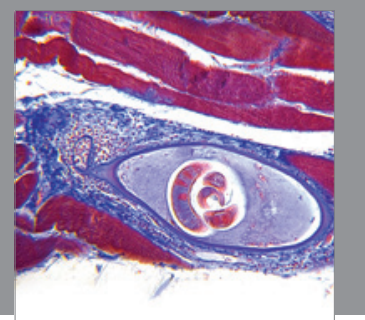

Gastroenterology

Research and Practice
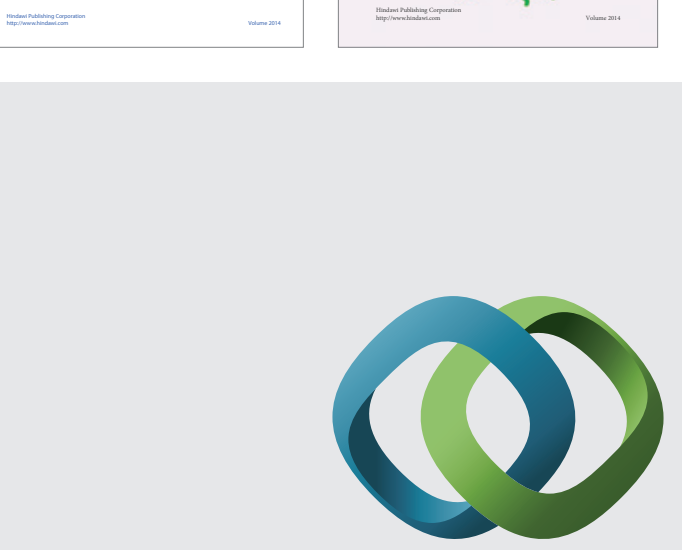

\section{Hindawi}

Submit your manuscripts at

http://www.hindawi.com
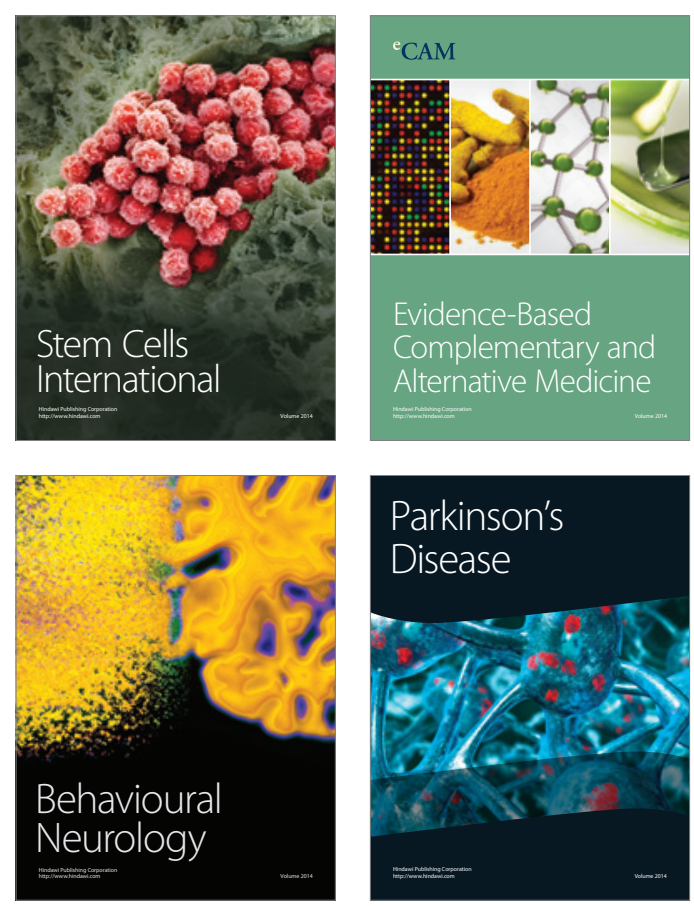

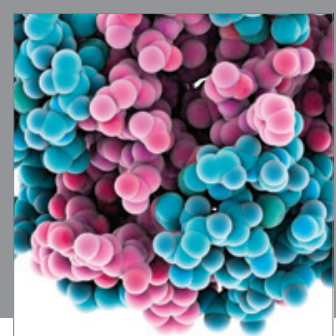

Journal of
Diabetes Research

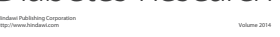

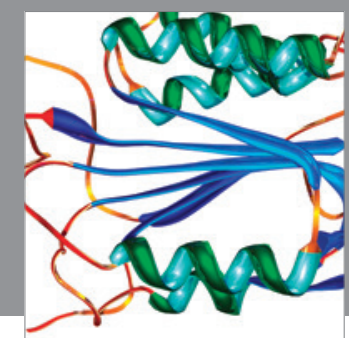

Disease Markers
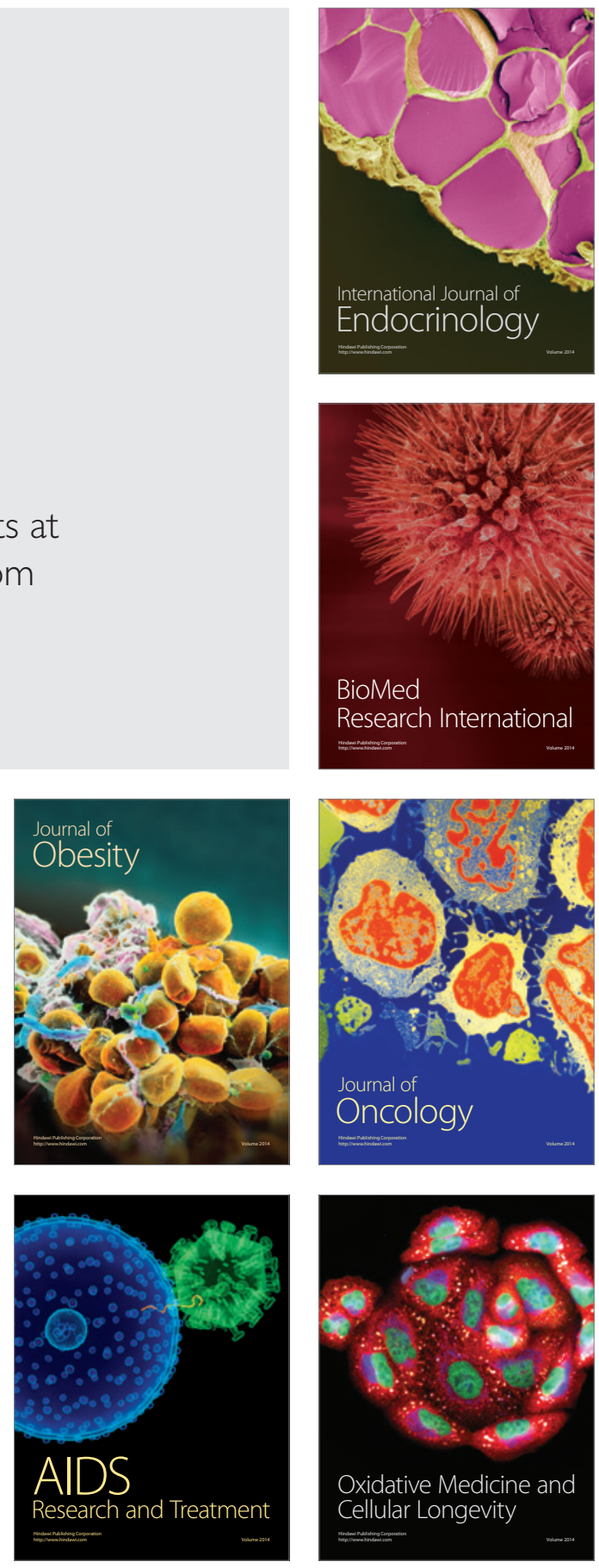